\title{
MeEting RePort For Seattle, 1997: SOME PERSONAL REMARKS
}

\author{
By Melbourne G. Briscoe
}

$\mathrm{T}$ he Oceanography Society (TOS) started in 1988; its first meeting was in Monterey in 1989. Since then, the biennial scientific meetings of the Society have been in St. Petersburg, Florida (1991), Seattle (1993), Newport, Rhode Island (1995), and most recently again in Seattle (1997). In addition, TOS has sponsored a Pacific Basin meeting in Honolulu in 1994, and its first international meeting in Amsterdam in 1996. Its second international meeting is planned for Paris, in June 1998, on the theme of Coastal and Marginal Seas. The attendance at these meetings is shown in Figure 1. You might argue that something awful happened between 1993 and 1994, or you might argue that the stable attendance at TOS meetings is around 300 , and that 91 and 93 were anomalies. This is an interesting problem in data analysis.

TOS invented the format of its meetings: plenary morning sessions built around a broad theme, with high-quality invited-only talks intelligible to a general oceanographic audience, and then afternoons of contributed posters related to the day's theme. The concept was to bring the community together in the plenary sessions and encourage communication and interdisciplinary discussions, and then provide an afternoon of unhurried "parallel-processing" and face-to-face discussions in the poster sessions. TOS has received a strong, even overwhelming, positive response to this format. Perhaps the most telling accolade is that other groups and societies are adopting the format as one clearly designed to improve science communications.

There is a downside to the TOS meeting format: there are only a few invited

Melbourne G. Briscoe, Secretary, ONR Code 322,800 N. Quincy St., Arlington, VA 22217, USA. briscom@onr.navy.mil speakers, and many folks feel that it is harder to prepare a good poster than it is to give an adequate 10-minute talk in the American Geophysical Union (AGU)style meeting with a large number of parallel sessions and short presentations. Thus, according to the evaluations we collect at the TOS meetings and the other comments we receive from attendees (and non-attendees!), many people do not attend TOS meetings because they perceive them as difficult venues in which to present their work. As a consequence, the attendance at TOS meetings is not large, thus the income from them for TOS is small (or negative), and thus TOS is always in a financially marginal situation.

It is not widely known that the AGU meetings are significant money makers for the Union: the abstract volumes use camera-ready copy, which is provided by the authors along with a payment for the publication of the abstract, and the abstract volumes are sold rather than given away. Every person attending pays a registration fee that supports the venue and infrastructure of the meetings, and coffee/soda at breaks; someone calculated that the coffee was about $\$ 25$ a cup, if you figured that was what the registration covered. Lots of people attend, because, they argue, "everyone is there" and there is a chance to show off your work; people forget that "everyone" is most likely in some other parallel session, and can't hear your 10-minute talk, so the few talk to the few. In fact, there are also complaints about the AGU-style meetings: no chance to learn anything outside your own little field because you have to be in

\section{Attendance at TOS Meetings}

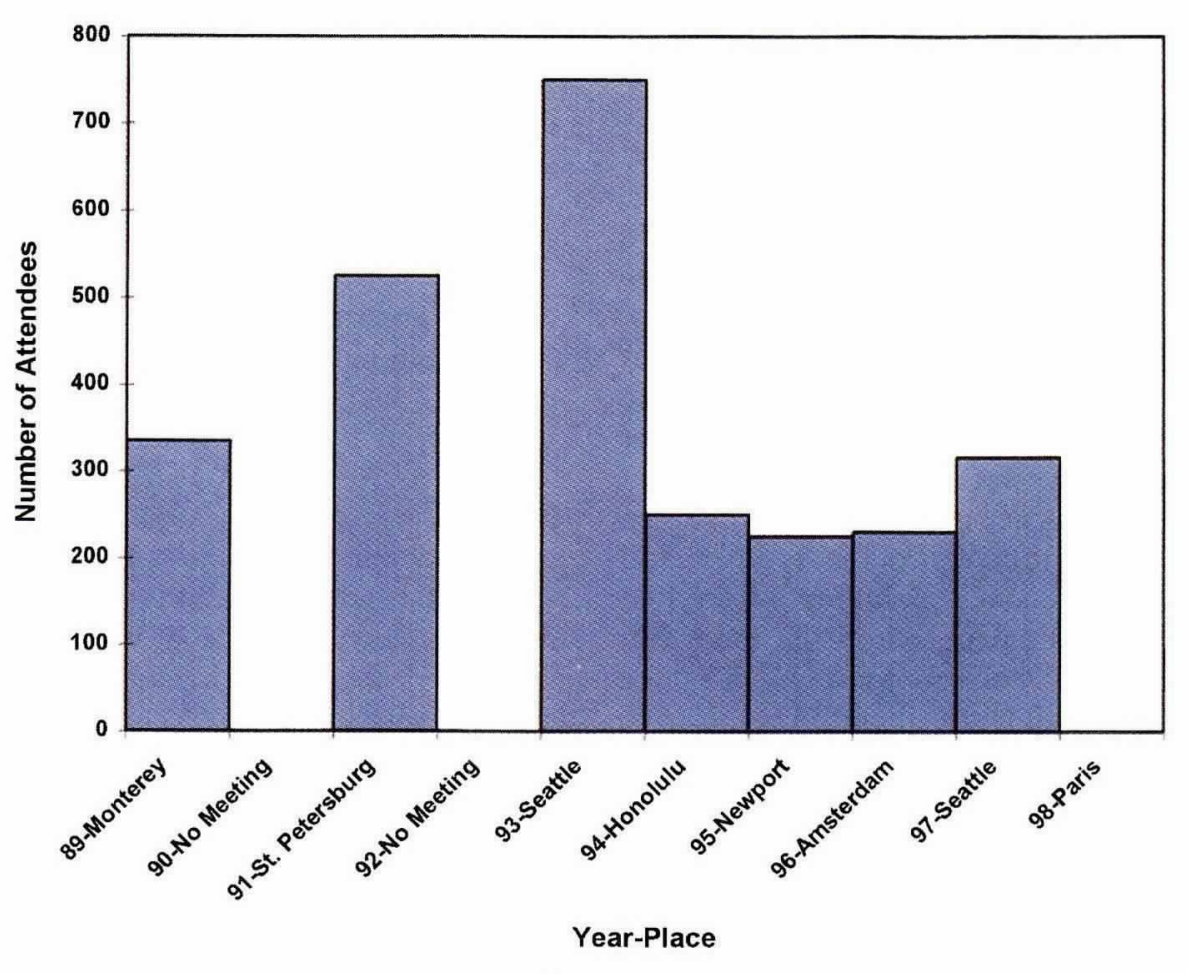

Figure 1 
your speciality sessions, and can ${ }^{\circ}$ go to the parallel sessions. Just as we would not want to have only AGU-style meetings as our only means of communications, we would not want to have TOSstyle meetings as our only mechanism to talk science. It is good that we have both.

Ideally. TOS would have at least one meeting a year, with enough themes so that everybody's favorite topics would get addressed relatively often. People would expect to present their work through posters, although a few folks would get invited to give presentations. The presentations are supposed to be broad looks across a topic, with excellent graphics/visuals; they are definitely harder work to put together than the afternoon posters! The tendency of an invited speaker to talk about just his/her own work. and to use vugraphs made on the airplane, is frowned upon, actively discouraged, and commented upon negatively afterward if it does happen. In this ideal world, lots of people would attend the TOS meetings because they would desire the opportunity to stretch their minds a bit and learn about the context. history, impact, and breadth of their field, and they would prefer the posters to the talks (to present their own work) because the posters are really meant to expose the nitty-gritty of a topic, and to motivate face-to-face discussion, whereas the talks are meant to give an overview and sense of perspective, not give the speaker's latest results. You might say the posters are for the presenters, whereas the talks are for the audience.

\section{Seattle 1997}

The 1997 TOS Seattle meeting, April 1-4, was on "Ocean Interfaces." The program contained sessions intended to examine the interface between the atmosphere and the ocean, between the upper-ocean (mixed layer) and the deeper ocean, between the sea and the sea floor, between science and policy, and between science and education. A total of 316 people attended. including 26 invited speakers and people from 13 countries; there were 136 posters presented. There were 38 students, including 4 Native Americans from the University of Alaska in Fairbanks, who attended along with their mentor on a TOS Scholarship grant from the Office of Naval Research (ONR) and National Oceanic and Atmospheric Administration (NOAA). The Scientific Committee on Oceanic Research (SCOR) supported the travel of several people from developing nations, and National Aeronautics and Space Administration (NASA) supported data access demonstrations.

Before the formal sessions on 1-4 April. the afternoon of March 31 was devoted to an introduction by Peter Cornillon to the NASA-supported data access demonstrations, and to a special education session about the oceanographer's role in implementing the U.S. National Academy of Sciences" recommendations for Standards for Science Education; the latter session generated considerable discussion and hallway comments. Everyone wants better science education; no one agrees on how to do it.

The formal plenary sessions contained some real gems of overview and mindstretching: Peter Liss's integrative talk on Iron. Biology, and Climate: John Knauss's retrospective on the Politics of Global Climate; Ann Gargett's remarkably interdisciplinary look at Physics to Fish: Connections Between Physics and Biology on a Variety of Scales: Walter Munk's bold synthesis and typically provocative presentation on The Moon and Mixing; John Baross' eye-opener on The Hot Deep Biosphere: and, in the final session on Policy and Perspectives. NOAA Administrator Jim Baker's thoughtful, humorous. and somewhat disconcerting look back at Lessons Learned-Reflections on the Last Four Years, which was presented on his behalf by NOAA Chief Scientist Al Beeton.

The poster sessions were equally engaging, with numerous extremely interesting, high-impact, and well-presented pieces of work. It is clear that we have turned the corner on poster presentations: no longer is it acceptable to just pin up a copy of your latest reprint; now the "gold standard" is color posters, live/interactive displays, and story-telling with a combination of minimal words and highly tuned pictures. I believe this is actually critical to the effective communication of today's science: as we move toward harder and harder topics, and more and more disciplines involved in a piece of work, and shorter and shorter attention spans, distilling the essence of a piece of work and articulating it to someone who is not a specialist in your favorite subject are essential to the useful explanation of your work. If you are the only person who understands it, and you cannot or do not communicate it, then the "standing on the shoulders of those who have gone before" aspect of science stops at your shoulders, which are not carrying their fair share of the burden.
Once again, in all respects other than attendance, it was an excellent meeting with many positive comments received afterward. The demographics tended toward the more senior members of the community, which was a shame. It is earlier in one"s career that the mind-stretching and networking and context may be more valuable. It is too bad that each attending senior person cannot commit to bringing along two more junior folks from his/her institution, in a kind of mentoring arrangement. In fact, a little of that was going on at the Seattle meeting (for example. the Native American student attendance), but very little.

Best quote of the meeting: "It's such a good meeting; it's a damn shame there are not more people here to enjoy it."

\section{Epilogue}

TOS meets next in Paris, June 1-4. 1998. at United Nations Educational, Scientific, and Cultural Organization (UNESCO) Headquarters in the seventh arrondissement, approximately in the shadow of the Eiffel Tower, and within walking distances of numerous small, inexpensive, and excellent hotels and restaurants. Because of the lack of a central hotel and the nature of the UNESCO facilities, some aspects of past TOS meetings will not be possible, such as group breakfasts; the good news is costs will be lower overall. in part because the UNESCO facilities are less costly than most.

What will not change in Paris will be the meeting format: morning plenary sessions with invited speakers on selected themes, and afternoon contributed poster sessions. The overall theme is Coastal and Marginal Seas, with daily sessions on Small Scale Processes: turbulence, particles, and transformations; Medium Scale Processes: transports, physical structures, and plankton distributions; Regional Scale Processes: circulation, budgets, and population dynamics; Policy and LateBreaking Events: and a special evening session on Global Ocean Observing System (GOOS).

Will this be a good meeting? Yes, without question. All the TOS meetings have been highly rated by the attendees, and the Paris meeting will probably be at the top of the list. judging on early interest and the timeliness and focus of the themes. Will this be a well-attended meeting? That is up to you. I look forward to seeing you there. $\square$ 